Giuseppe Citerio

Peter J. D. Andrews

\section{Refractory elevated intracranial pressure: intensivist's role in solving the dilemma of decompressive craniectomy}

Published online: 13 March 2007

(C) Springer-Verlag 2007

The online version of the original article can be found at: http://dx.doi.org/10.1007/s00134-006-0381-5

\section{G. Citerio (区)}

Ospedale San Gerardo, Neurorianimazione, Dipartimento di Medicina Perioperatoria e Terapie Intensive,

Via Pergolesi 33, 20052 Monza, Italy

e-mail: g.citerio@hsgerardo.org

\section{P. J. D. Andrews}

Western General Hospital, Department of Anaesthetics, Intensive Care and Pain Medicine,

Crewe Road, EH4 2XU, Edinburgh, UK

\section{Intensive Care Med (2007) 33:45 - 48}

On page 47 "(c) there is an indication of a high global cerebral oxygen extraction, (AJDO2 < 3.2 vol \%) [15];" should be "(c) there is an indication of a low global cerebral oxygen extraction, (AJDO2 < 3.2 vol \%) [15];".

Acknowledgements. The data on the incidence of the standard medical and surgical therapies failure comes from an analysis on the Neurolink database conceived and carried out by Nino Stocchetti. The manuscript by Stocchetti, Zanaboni, Colombo, Canavesi, Citerio, Beretta, Longhi, and Roncati Zanier titled "Refractory intracranial hypertension and second tier therapies in traumatic brain injury", submitted for publication, summarises this analysis and its impact on outcome. Data published, anticipation of the research results, comes from a personal communication with Nino Stocchetti, which therefore we would like to sincerely acknowledge. 